\title{
Engineered biochar from pine wood: Characterization and potential application for removal of sulfamethoxazole in water
}

\author{
Hyun Min Jang', Seunghyun Yoo ${ }^{2}$, Sunkyu Park ${ }^{2}$, Eunsung Kan ${ }^{1,3^{\dagger}}$ \\ ${ }^{1}$ Department of Agricultural and Biological Engineering \& Texas A\&M AgriLife Research Center at Stephenville, Texas A\&M University, College Station, \\ USA \\ ${ }^{2}$ Department of Forest Biomaterials, North Carolina State University, Raleigh, USA \\ ${ }^{3}$ Department of Wildlife, Sustainability, and Ecosystem Sciences, Tarleton State University, Stephenville, USA
}

\begin{abstract}
The adsorption of sulfamethoxazole (SMX) onto a $\mathrm{NaOH}$-activated pine wood-derived biochar was investigated via batch experiments and models. Surprisingly, the maximum adsorption capacity of activated biochar for SMX (397.29 mg/g) was superior than those of pristine biochars from various feedstock, but comparable to those of commercially available activated carbons. Elovich kinetic and Freundlich isotherm models revealed the best fitted ones for the adsorption of SMX onto the activated biochar indicating chemisorptive interaction occurred on surface of the activated biochar. In addition, the intraparticle diffusion limitation was thought to be the major barrier for the adsorption of SMX on the activated biochar. The main mechanisms for the activated biochar would include hydrophobic, $\pi-\pi$ interactions and hydrogen bonding. This was consistent with the changes in physicochemical properties of the activated biochar (e.g., increase in $\mathrm{sp}^{2}$ and surface area, but decrease in the ratios of $\mathrm{O} / \mathrm{C}$ and $\mathrm{H} / \mathrm{C}$ ).
\end{abstract}

Keywords: Activated biochar, Antibiotics, Sulfamethoxazole (SMX), Water treatment, $\pi-\pi$ interaction

\section{Introduction}

Various pharmaceutical compounds released to environments have attracted rising attention due to their adverse effects such as endocrine disruption and prevalence of antibiotic resistance genes [1]. According to recent literatures [2], the low metabolic rates of many pharmaceuticals in human and animals resulted in high environmental risks. Due to high cost-effectiveness, sulfamethoxazole (SMX) is one of the most widely used synthetic sulfonamides antibacterial agents to treat diseases and infections for human [3]. In addition, it is used for feed additives to promote growth rate and weigh gain of food animals [4]. As a consequence, it has been frequently detected in various environmental matrices including soil, sediment, river, surface and ground water $[5,6]$.

Several remediation technologies such as adsorption $[7,8]$, ozonation [9], photolysis [10], chemical [3] and electrochemical oxidation [11] are available for elimination of SMX from various water bodies. Adsorption is considered as one of the practical options for removal of SMX mainly due to its simple operation,

This is an Open Access article distributed under the terms of the Creative Commons Attribution Non-Commercial License (http://creativecommons.org/licenses/by-nc/3.0/) which permits unrestricted non-commercial use, distribution, and reproduction in any medium, provided the original work is properly cited.

Copyright (C) 2019 Korean Society of Environmental Engineers no generation of harmful byproducts and cost-effectiveness [12]. Recently, adsorption of SMX on various materials has been investigated including clay minerals [13], graphene oxide [14], activated carbons (ACs) [15] and carbon nanotubes (CNTs) [1, 16]. Although some materials such as CNTs and graphene oxide have shown high adsorption capacities for SMX, high costs associated with manufacturing and disposal of these materials limited their practical application in fields [17].

As an alternative adsorbent, biochar (BC), which is a carbonaceous material $(\mathrm{CM})$ produced by pyrolysis of biomass, has received enormous attention due to its low costs and adsorption of various contaminants [7]. Many BCs derived from paper mill sludge [18], bamboo [19], giant reed [8], herb-residue [20], crop straw [21], pine wood [22, 23] and anaerobically digested bagasse [24] have been applied to elimination of SMX. Unfortunately, these BCs showed the limited adsorption capacities for SMX $(<$ $100 \mathrm{mg} \mathrm{SMX/g} \mathrm{BC).} \mathrm{Therefore,} \mathrm{possible} \mathrm{activation} \mathrm{and} \mathrm{mod-}$ ification of raw BCs are suggested to enhance their adsorption capacity.

\footnotetext{
${ }^{\dagger}$ Corresponding author

Email: eunsung.kan@ag.tamu.edu

Tel: +1-254-968-4144 Fax: +1-254-968-3759

ORCID: 0000-0001-6298-6096
}

Received October 10, 2018 Accepted December 1, 2018 
According to Thangalazhy-Gopakumar et al. [25], pine wood is one of the most abundant feedstock in the southern states in U.S. while making it an excellent precursor for BC. To date, a few studies have investigated the adsorption of SMX in water by the pine wood-derived BC (PBC) [22, 23]. However, these studies showed the limited adsorption capacities for SMX and have not investigated the detailed adsorption characteristics such as kinetic and isotherm modeling. The present study reports the detailed adsorption characteristics of pine wood-derived activated BC for SMX. This work also illustrated possible mechanisms for the adsorption of SMX onto the $\mathrm{NaOH}$-activated PBC.

\section{Materials and Methods}

\subsection{Reagents}

All chemicals including SMX in the present study were purchased from Sigma-Aldrich Co. (Saint Louis, MO, USA) (Table 1). Based on the solubility of SMX in water at ambient conditions [26], 10-100 mg/L of SMX were used for the adsorption experiments in this study. Four commercial ACs used in the present study were obtained from Sigma-Aldrich Co. (Darco ${ }^{\circledR}$ G-60, Norit ${ }^{\circledR}$ GAC and Norit ${ }^{\circledR}$ GA1) and Calgon Carbon Corp. (Calgon F400).

\subsection{Preparation of $\mathrm{PBC}$}

Pine wood (Pinus taeda) was used for production of PBC as reported in Jang et al. [27]. Briefly, the air-dried and sieved (20 mesh) pine wood was carbonized using the preheated pyrolysis furnace (MTI Corporation, Richmond, CA, USA) under $300^{\circ} \mathrm{C}$ for $15 \mathrm{~min}$ with $1 \mathrm{~L} / \mathrm{min}$ of $\mathrm{N}_{2}$ flow. The pristine $\mathrm{PBC}$ was designated as "R-PBC".

\subsection{Activation of $\mathrm{PBC}$}

Activation of R-PBC was carried out as follows: (1) Soaking 3 g of R-PBC in $40 \mathrm{~mL}$ of $4 \mathrm{M} \mathrm{NaOH}$ solution for $2 \mathrm{~h}$ at room temperature, (2) Pyrolyzing the dried $\mathrm{NaOH}$-treated R-PBC under $800^{\circ} \mathrm{C}$ for $2 \mathrm{~h}$ with a heating rate of $3^{\circ} \mathrm{C} / \mathrm{min}$ while maintaining oxygen limited conditions ( $2 \mathrm{~L} / \mathrm{min}$ of $\mathrm{N}_{2}$ flow), and (3) Washing the BC with $0.1 \mathrm{M} \mathrm{HCl}$ solution $(200 \mathrm{~mL}$ ) followed by a deionized (DI) water until the $\mathrm{pH}$ of $\mathrm{BC}$ reached 7.0. The washed and dried $\mathrm{NaOH}$-activated PBC was designated as "A-PBC”.

\subsection{Characterization of $\mathrm{R}$ - and A-PBCs}

The physicochemical properties of the R- and A-PBCs were inves- tigated in detail. Elemental composition analyzer (PerkinElmer 2400 Series II, MA, USA) and scanning electron microscope (SEM) (FEI Verios 460, Hillsboro, OR, USA) were used to evaluate the elemental compositions and the morphology, respectively. Thermogravimetric analysis (TA Instruments, New Castle, DE, USA) was used to evaluate the contents of fixed carbon, volatile compounds, and ash in R- and A-PBCs in accordance with ASTM standard D7582-15 [28]. Fourier transform infrared (FT-IR) spectroscopic analysis was conducted using a FT-IR spectrometer (Bruker Optik GmbH, Ettlingen, Germany). Brunauer-EmmettTeller (BET) surface area and pore-size distribution were evaluated on the basis of the measurements relating to $\mathrm{N}_{2}$ adsorption with an apparatus at $77 \mathrm{~K}$ (Micromeritics Gemini VII 2390p, Norcross, GA, USA). X-ray photoelectron spectroscopy (XPS) analysis was performed using XPS/UPS -SPECS System (SPECS Surface Nano Analysis GmbH, Berlin, Germany) equipped with a monochromatic $\mathrm{Mg} \mathrm{K} \alpha$ radiation to quantify carbon-oxygen functional groups. All spectra were acquired from a sample area of $1 \mathrm{~mm}$ $\times 1 \mathrm{~mm}$. The resolution of PHOIBOS 150 photoelectron analyzer is lower than $1 \mathrm{eV}$. The $\mathrm{pH}$ of zero point charges ( $\mathrm{pH}_{\mathrm{PZC}}$ ) analysis was conducted as described previously [27]. Briefly, 0.01 M of $50 \mathrm{~mL} \mathrm{NaCl}$ solution was used to maintain the ion strength and the initial $\mathrm{pH}$ of solution was adjusted ranged from 3.0 to 10.0. The final $\mathrm{pH}$ of solution was measured after $2 \mathrm{~d}$ incubation with $0.01 \mathrm{~g}$ of $\mathrm{BC}$ at $20^{\circ} \mathrm{C}$ and $150 \mathrm{rpm}$. The $\mathrm{pH}_{\mathrm{PZC}}$ was calculated by the $\Delta \mathrm{pH}=0$.

Energy loss spectroscopy (EELS) was conducted to analyze $\mathrm{sp}^{2}$ content of the BCs (R- and A-PBCs). As described by Jang et al. [27], thin TEM samples of R- and A-PBCs were prepared by using UC7 Ultramicrotome (Leica Microsystems Inc. Buffalo Grove, IL, USA). Electron energy loss spectra for R- and A-PBCs were collected with the electron energy loss spectrometer (Gatan, Pleasanton, CA, USA) attached to probe aberration corrected scanning transmission electron Microscope (FEI Titan 80-300, Hillsboro, OR, USA). For further calculation, the carbon K-edge energy loss spectrum was deconvolved into three Gaussian spectra [29].

The $\mathrm{sp}^{2}$ content is defined as a relative value between the sample $1 \mathrm{~s}$ to $\pi^{*}$ transition peak area ratio and that of graphite as calculated by Eq. (1) [30]:

$$
S P^{2}=\frac{\left[\frac{\operatorname{area}\left(\pi^{*}\right)}{\operatorname{area}\left(\pi^{*}+\sigma^{*}\right)}\right]_{\text {sample }}}{\left[\frac{\operatorname{area}\left(\pi^{*}\right)}{\operatorname{area}\left(\pi^{*}+\sigma^{*}\right)}\right]_{\text {Graphite, reference }}}
$$

Table 1. Physical and Chemical Characteristics of Sulfamethoxazole (SMX)

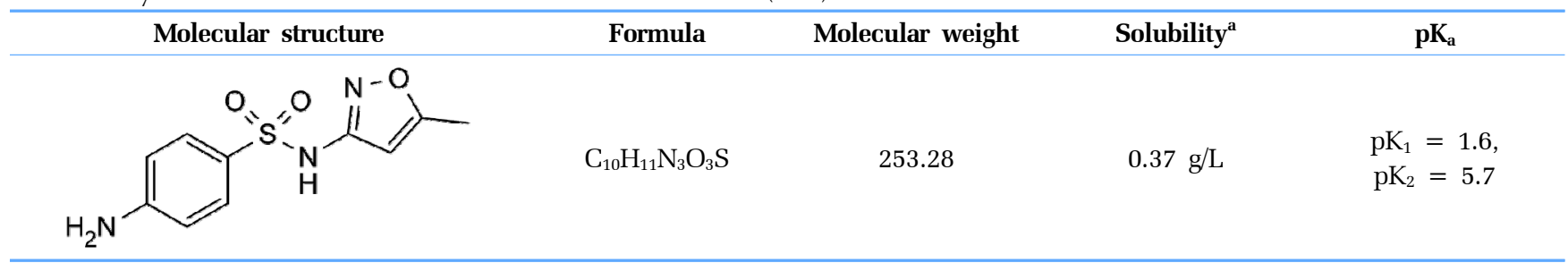

\footnotetext{
${ }^{\mathrm{a} A t}$ ambient temperature [26].
} 
where the transition at $285.0 \mathrm{eV}$ indicates the electronic transition from carbon $1 \mathrm{~s}$ orbital to $\mathrm{C}=\mathrm{C} \pi^{*}$ bonding orbital, the second transition at $292.0 \mathrm{eV}$ indicates the electronic transition from carbon $1 \mathrm{~s}$ orbital to $\mathrm{C}-\mathrm{C} \sigma^{*}$ bonding orbital, and the third transition at $298.0 \mathrm{eV}$ indicates the electronic transition from carbon $1 \mathrm{~s}$ orbital to $\mathrm{C}=\mathrm{C} \sigma^{*}$ bonding orbital [29, 31, 32].

\subsection{Batch Adsorption Experiments}

The effects of initial solution $\mathrm{pH}$ on adsorption of SMX was conducted at $\mathrm{pH} 1-10$. Before mixing with the BCs, the solution $\mathrm{pH}$ was set to the desired $\mathrm{pH}$ by adding $0.1 \mathrm{M}$ of $\mathrm{HCl}$ or $\mathrm{NaOH}$ solution. The foil covered glass bottles were agitated at 150 $\mathrm{rpm}$ and $20^{\circ} \mathrm{C}$ for $5 \mathrm{~d}$. To quantitatively evaluate the contributions of individual SMX species to overall sorption at a tested $\mathrm{pH}$ value, the following empirical model was used (Eq. (2)) [33]:

$$
K_{d}=K_{d} \alpha^{-}+K_{d}^{0} \alpha^{0}+K_{d}^{+} \alpha^{+}
$$

where $K_{d}(\mathrm{~L} / \mathrm{kg})$ is overall sorption coefficient and $K_{d}^{-}, K_{d}{ }^{0}$ and $K_{d}^{+}$are the sorption coefficients and $\alpha^{-}, \alpha^{0}$ and $\alpha^{+}$are the mass fraction for the $\mathrm{SMX}^{-}, \mathrm{SMX}^{0}$ and $\mathrm{SMX}^{+}$, respectively.

The adsorption kinetic study was conducted by stirring 0.01 $\mathrm{g}$ of A-PBC and $0.1 \mathrm{~L}$ of SMX solution (20 and $100 \mathrm{mg} / \mathrm{L}$ ) at $\mathrm{pH} 4$ which was determined as the optimum $\mathrm{pH}$ from the above experiments. The aqueous samples were taken at a regular interval for $2 \mathrm{~d}$. In addition, the adsorption experiments for isotherm study were conducted by vigorously stirring $0.1 \mathrm{~L}$ of SMX solution (10 to $100 \mathrm{mg} / \mathrm{L}, \mathrm{pH}$ 4) and $0.01 \mathrm{~g}$ of A-PBC for $5 \mathrm{~d}$ to reach equilibrium. The SMX concentration in water was evaluated and used for development of an appropriate isotherm model.

During the batch adsorption experiments, the samples were centrifuged and then filtered using a $0.45 \mu \mathrm{m}$ syringe filter. The concentration of SMX in filtrated solution was measured by a HPLC (LC-2030C model, SHIMADZU Corp., Torrance, CA, USA) with a C-18 column (Aeris PEPTIDE 3.6 $\mu \mathrm{m}$ XB-C18, Phenomenex Inc., Torrance, CA, USA) and a UV-vis detector operating at wavelength of $265 \mathrm{~nm}$. More detailed information about analysis of SMX by a HPLC was described in previously [27].

Adsorption capacity at time $\mathrm{t}, \mathrm{Q}_{\mathrm{t}}(\mathrm{mg} / \mathrm{g})$ was calculated by Eq. (3):

$$
Q_{t}=\frac{\left(C_{0}-C_{t}\right) \times V}{M}
$$

where $C_{0}$ and $C_{t}$ are the SMX concentration of initial and at time $\mathrm{t}(\mathrm{mg} / \mathrm{L})$, respectively, $V$ is the volume of SMX solution (L) and $M$ is the $\mathrm{g}$ of $\mathrm{BC}$ used in study.

The sum of squared error (SSE) was determined according to Eq. (4):

$$
S S E=\sqrt{\frac{\sum\left(Q_{e}-Q_{c}\right)^{2}}{N}}
$$

where $Q_{e}$ and $Q_{c}$ are the observed and calculated value of adsorp- tion capacity $(\mathrm{mg} / \mathrm{g})$, respectively, and $N$ is the number of measurements.

\subsection{Adsorption Kinetic and Isotherm Models}

The six adsorption kinetic models including pseudo-first order, pseudo-second order, Elovich, two-compartment first order, intra-particle diffusion and liquid film diffusion can be represented as follows (Eq. (5)-(10)):

Pseudo-first order (PFO): $Q_{t}=Q_{e}\left(1-\exp \left(-K_{1} t\right)\right)$

Pseudo-second order (PSO): $Q_{t}=\frac{K_{2} Q_{e}^{2} t}{1+K_{2} Q_{e} t}$

Elovich: $Q_{t}=\left(\frac{1}{b}\right) \ln a b+\left(\frac{1}{b}\right) \ln t, t_{0}=\frac{1}{a b}$

Intra-particle diffusion: $Q_{t}=K_{i} \sqrt{t}+C_{i}$

Liquid file diffusion: $\ln (1-F)=-K_{f d} t, F=\frac{Q_{t}}{Q_{e}}$

Two-compartment first order:

$$
\frac{Q_{t}}{Q_{t=\infty}}=F_{\text {fast }}\left(1-e^{-t K_{\text {fast }}}\right)+F_{\text {slow }}\left(1-e^{-t p^{-t K_{\text {slow }}}}\right)(10)
$$

where $\mathrm{Q}_{\mathrm{e}}=$ adsorption capacity (mg/g) at equilibrium time, $\mathrm{Q}_{\mathrm{t}}$ $=$ adsorption capacity (mg/g) at time $\mathrm{t}(\mathrm{min}), \mathrm{K}_{1}=$ rate constant of pseudo-first order, $\mathrm{K}_{2}=$ rate constant of pseudo-second order, $\mathrm{a}=$ rate constant of chemisorption, $\mathrm{b}=$ constant of the surface coverage, $\mathrm{K}_{\mathrm{i}}=$ intra-particle diffusion rate constant $\left(\mathrm{mg} \cdot \mathrm{min}^{0.5} / \mathrm{g}\right.$ ), $\mathrm{C}_{\mathrm{i}}=\mathrm{a}$ constant $(\mathrm{mg} / \mathrm{g}), \mathrm{K}_{\mathrm{fd}}=$ adsorption rate constant, $\mathrm{F}_{\text {fast }}=$ mass fraction of fast, $\mathrm{F}_{\text {slow }}=$ mass fraction of slow, $\mathrm{K}_{\text {fast }}=$ first order rate constant for transfer into fast $\left(\mathrm{h}^{-1}\right), \mathrm{K}_{\text {slow }}=$ first order rate constant for transfer into slow $\left(\mathrm{h}^{-1}\right), \mathrm{h}=$ hour.

In this study, three isotherm models including Langmuir, Freundlich and Temkin models were used to fit the experimental data (Eq. (11)-(13)):

Langmuir: $Q_{e}=\frac{Q_{m} K_{L} C_{e}}{1+K_{L} C_{e}}, R_{L}=\frac{1}{1+K_{L} C_{0}}$

Freundlich: $Q_{e}=K_{f} C_{e}^{1 / n_{f}}$

Temkin: $Q_{e}=\frac{R T}{b_{T}} \ln \left(K_{T} C_{e}\right)$

Where $\mathrm{Q}_{\mathrm{e}}=$ adsorption capacity (mg/g) at equilibrium time, $\mathrm{Q}_{\mathrm{m}}=$ maximum adsorption capacity $(\mathrm{mg} / \mathrm{g}), \mathrm{K}_{\mathrm{L}}=$ Langmuir constant, $\mathrm{C}_{\mathrm{e}}=$ equilibrium concentration $(\mathrm{mg} / \mathrm{L}), \mathrm{R}_{\mathrm{L}}=$ separation constant, $\mathrm{K}_{\mathrm{f}}$ and $\mathrm{n}_{\mathrm{f}}=$ Freundlich constant, $\mathrm{R}=$ universal gas constant $(8.314 \mathrm{~J} / \mathrm{mol}), \mathrm{T}=$ temperature in terms of Kelvin, $\mathrm{b}_{\mathrm{T}}$ $=$ Temkin constant, $\mathrm{K}_{\mathrm{T}}=$ equilibrium bond constant related to the maximum energy of bond, $t=$ time $(\min )$. 


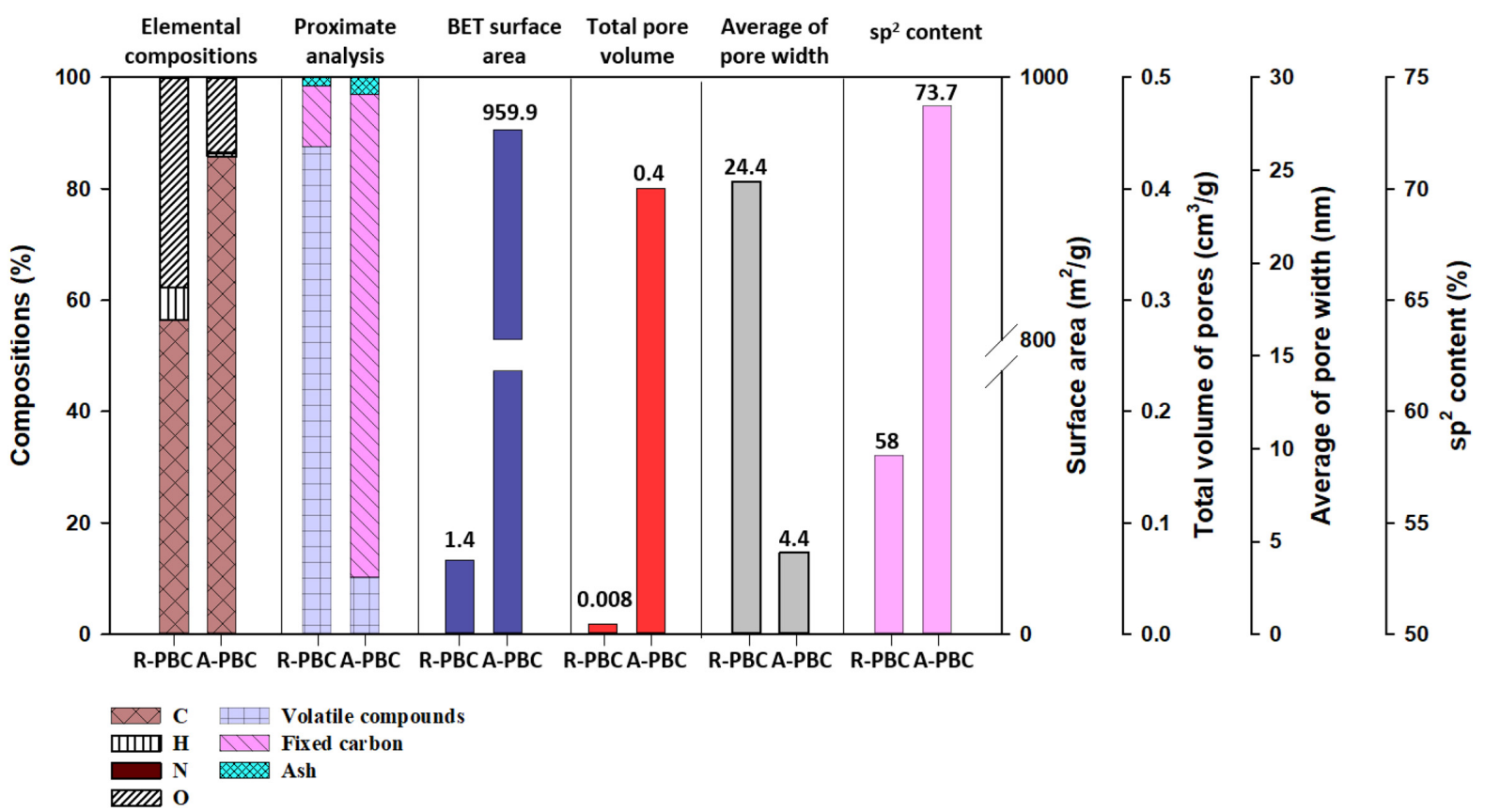

Fig. 1. Physical, chemical and textual characteristics of R- and A-PBCs.

\section{Results and Discussion}

\subsection{Effect of Activation on Physicochemical Properties of $\mathrm{BC}$}

The physicochemical properties of R-PBC and A-PBC are presented in Fig. 1. For the elemental compositions, the $\mathrm{C}$ content increased from 56.4 to $85.8 \%$ after activation, whereas the $\mathrm{O}$ and $\mathrm{H}$ contents decreased from 37.6 to $13.5 \%$ and from 5.9 to $0.5 \%$, respectively. With decomposition of $\mathrm{O}$ and $\mathrm{H}$ under high temperature [27], significant structural changes occurred in A-PBC. As shown in Fig. 2, the ratio of $\mathrm{O} / \mathrm{C}$ decreased from 0.67 to 0.16 while the ratio of $\mathrm{H} / \mathrm{C}$ decreased from 0.10 to $5.8 \times 10^{-3}$, respectively. The decrease in the ratios of $\mathrm{O} / \mathrm{C}$ and $\mathrm{H} / \mathrm{C}$ represented decarboxylation (i.e., loss of $\mathrm{CO}_{2}$ ) and demethylation (i.e., loss of $\mathrm{CH}_{3}$ ) [34], respectively, suggesting the formation of porous polyaromatic structures with rich carbon content after the $\mathrm{NaOH}$ activation of R-PBC. Interestingly, the $\mathrm{O} / \mathrm{C}$ and $\mathrm{H} / \mathrm{C}$ of $\mathrm{A}-\mathrm{PBC}$ were lower than those of other BCs made from grasses, crop residues, manure and sewage sludge, but were close to that of powder activated carbon (Fig. 2). The low $\mathrm{O} / \mathrm{C}$ and $\mathrm{H} / \mathrm{C}$ of $\mathrm{A}-\mathrm{PBC}$ indicated high hydrophobicity and aromaticity in A-PBC which would be closely related to adsorption characteristics of A-PBC for hydrophobic contaminants.

Fig. 1 showed the calculated $\mathrm{sp}^{2}$ content of R-PBC and A-PBC. Interestingly, A-PBC showed higher $\mathrm{sp}^{2}$ content $(73.7 \%)$ than that of R-PBC (58.0\%). Similary, Yoo et al. [30] reported the increase in $\mathrm{sp}^{2}$ content as a function of pyrolysis temperature during the pyrolysis of pine wood. Thus, the increase in $\mathrm{sp}^{2}$ content in A-PBC might be due to the increase in pyrolysis temperature $\left(800^{\circ} \mathrm{C}\right)$ during $\mathrm{NaOH}$ activation of R-PBC. Also, this was consistent with ${ }^{13} \mathrm{CDP} / \mathrm{NMR}$ data (i.e. a growing aromatic structure after $\mathrm{NaOH}$ activation of pine BC) which reported by Park et al. [35].
Furthermore, FTIR spectrum of A-PBC exhibited the negligible functional groups and more similar to commercial ACs which have high hydrophobicity (Fig. S1).

After $\mathrm{NaOH}$ activation, changes in the morphology of BC surface were observed (Fig. S2). The sponge-like structure in A-PBC indicated the development of micro/meso-pore on the surface. This is highly supported by the data from the textural analysis (i.e., decreased in average of pore width and increased in volume of

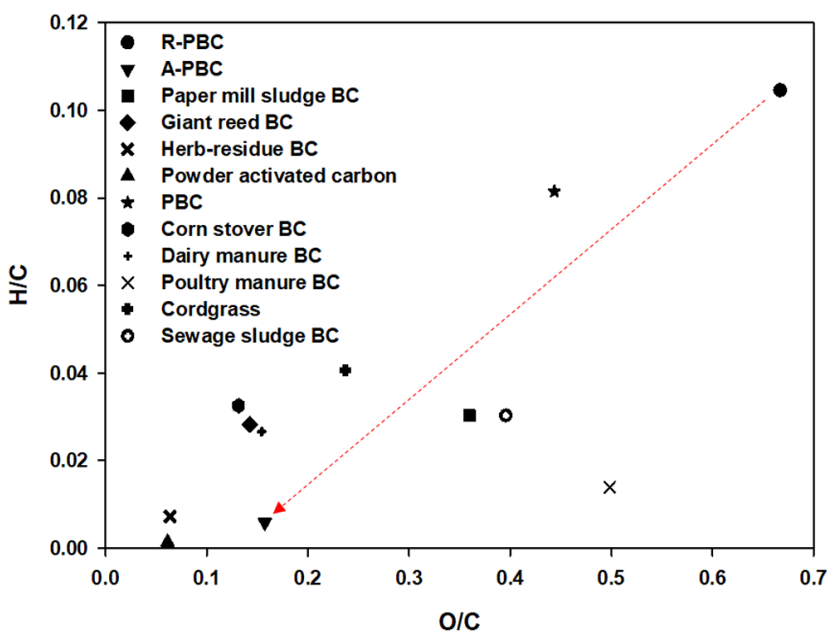

Fig. 2. Van Krevelen plot of elemental ratios for R- and A-PBCs. Other BCs or ACs derived from paper mill sludge [18], giant reed [8], herb-residue [20], powered ACs [23], corn stover, dairy manure, poultry manure [47], cordgrass, pine wood [48] and sewage sludge [49] were used to fit in this study. Red arrow indicates the change in properties between R- and A-PBC. 
pores) (Fig. 1). With the well-developed structure, high BET surface area $\left(959.9 \mathrm{~m}^{2} / \mathrm{g}\right)$ was achieved in A-PBC. Thus, the activation of PBC increased hydrophobicity and surface area which can lead to more heterogeneous adsorption characteristics [21, 36].

\subsection{Effects of Initial pH on Adsorption Capacity}

Recently, a strong relationship between SMX species and surface charge of CMs has been reported in the literatures [8, 37]. To take the SMX property into consideration, adsorption capacities ( $\mathrm{Q}_{\mathrm{e}}, \mathrm{mg} / \mathrm{g}$ ) of SMX on the R-PBC and A-PBC were investigated at various initial solution $\mathrm{pH}$ (Fig. 3). Both BCs exhibited similar $\mathrm{pH}$-dependent adsorption patterns. The $\mathrm{Q}_{\mathrm{e}}$ values increased with increasing $\mathrm{pH}$ from 1 to 4 and then reached the maximum at $\mathrm{pH} 4$ for both BCs (58.91 mg/g for R-PBC and $437.36 \mathrm{mg} / \mathrm{g}$ for A-PBC). Meanwhile, the significantly decreased $Q_{e}$ values were observed at $\mathrm{pH}$ higher than 7. Similar results were found from the pH-dependent SMX adsorption on bamboo-derived BC [19].

The higher $\mathrm{K}_{\mathrm{d}}^{0}$ than both $\mathrm{K}_{\mathrm{d}}{ }^{+}$and $\mathrm{K}_{\mathrm{d}}{ }^{-}$at the $\mathrm{pH}$ of 2-5 (for R-PBC) and 1-6 (for A-PBC) was observed in both R-PBC and A-PBC (Table S1), indicating the importance of $\mathrm{SMX}^{0}$ species to the overall adsorption. At the $\mathrm{pH}$ ranges between 1 and 5, the contribution of $\mathrm{SMX}^{0}$ species to the overall adsorption was higher than 51\% (Fig. S3). This was consistent with the data from Zheng et al. [8] who reported significant contribution of $\mathrm{SMX}^{0}$ species to the overall adsorption on giant reed BC. Interestingly, between $\mathrm{pH} 1$ and 5 , the contribution of $\mathrm{SMX}^{0}$ species to the overall adsorption on A-PBC was higher than that of R-PBC, suggesting that activation process enhanced hydrophobic interaction as well $\pi-\pi$ interaction which was predominant adsorption mechanisms for SMX species on A-PBC [16, 38].

As shown in Fig. 3, the $\mathrm{SMX}^{+}$and $\mathrm{SMX}^{-}$are the dominant species at $\mathrm{pH}<\mathrm{pK}_{\mathrm{a} 1}=1.6$ and $\mathrm{pH}>\mathrm{pK}_{\mathrm{a} 2}=5.7$, respectively, and $\mathrm{SMX}^{0}$ is dominant at $\mathrm{pH}$ between $\mathrm{pK}_{\mathrm{a} 1}$ and $\mathrm{pK}_{\mathrm{a} 2}$. In addition, it is assumed that the surface charge of $\mathrm{BC}$ was protonated (i.e., positive charge) when the solution $\mathrm{pH}$ was lower than the $\mathrm{pH}_{\mathrm{PZC}}$ of

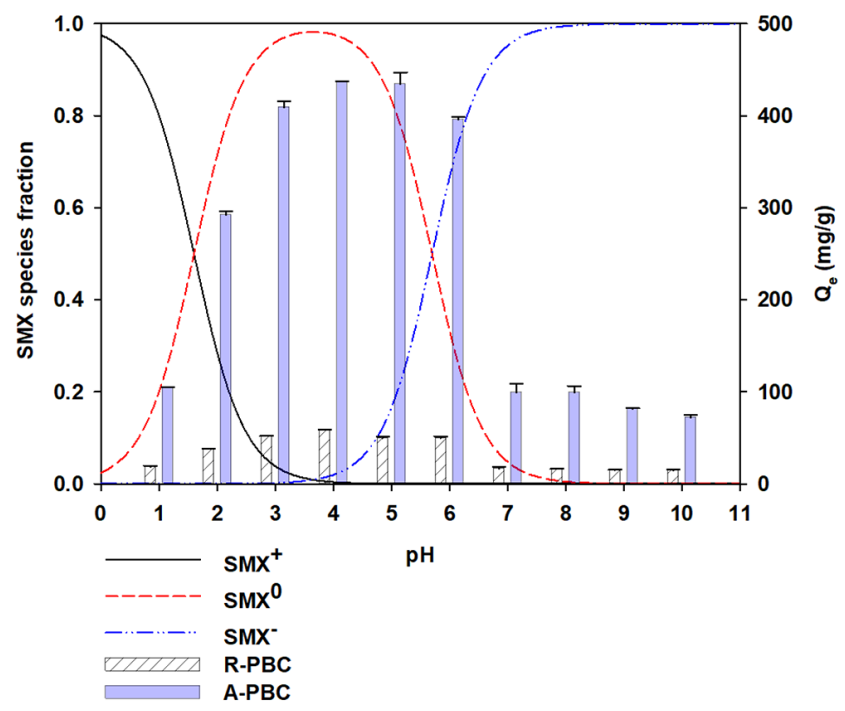

Fig. 3. pH-dependent SMX species and adsorption capacities of Rand A-PBCs.
$\mathrm{BC}$, otherwise it was the negative. Considering the $\mathrm{pH}_{\mathrm{PZC}}$ of $\mathrm{R}-\mathrm{PBC}$ (5.08) and A-PBC (6.83) (Table S1), a strong electrostatic repulsion between the SMX species and surface of BCs would occur at high $\mathrm{pH}(>7)$ or low $\mathrm{pH}(<1)$ resulting in relatively low value of $\mathrm{Q}_{\mathrm{e}}$. However, it is interesting to note that some portion of SMX (72-98 mg/g) was still adsorbed on the A-PBC at high $\mathrm{pH}$ $(>7)$, although a strong electrostatic repulsion would be expected between the SMX ${ }^{-}$and negative charged surface of BCs. This was explained by a strong negative charged assistant hydrogen bond (CAHB) along with oxygen-containing group on surface [20]. Teixidó et al. [33] and $\mathrm{Yu}$ et al. [16] reported that $-\mathrm{NH}_{2}$ and $-\mathrm{SO}_{2} \mathrm{NH}$ - groups in sulfonamides can interact with oxygen-containing group on surface of $\mathrm{CM}_{\mathrm{S}}$. Thus, it is hypothesized that A-PBC has a high potential for hydrogen bonding accepting or donating due to its plenty of oxygen-containing group on surface of A-PBC (Table S1). As expected, the significant decrease in $\mathrm{Q}_{\mathrm{e}}$ values (about $291 \mathrm{mg} / \mathrm{g}$ at $\mathrm{pH} 2$ and $104 \mathrm{mg} / \mathrm{g}$ at $\mathrm{pH}$ 1) were also observed at low $\mathrm{pH}$ due to the much less hydrophobicity of A-PBC with abundant ionized forms and the inhibited Lewis acid-base interaction [1].

$\pi-\pi$ electron donor-acceptor (EDA) interaction is one of the possible mechanisms for the adsorption of sulfonamides on BC surface $[19,39]$. SMX has a strong $\pi$-electron acceptor nature due to its $p$-amino rings (donates loan pair electrons to the benzene ring) and $\mathrm{N}$ and/or O-hetero-aromatic rings (contribution to electronic resonance), while the graphite structure $\pi$-electron of BC can act as electron donor $[16,19]$. The ability for $\pi-\pi$ EDA interaction of different SMX species follows the order of $\mathrm{SMX}^{+}>$ $\mathrm{SMX}^{0}>\mathrm{SMX}^{-}$due to the decrease in $\pi$-withdrawing ability resulted from deprotonation of $-\mathrm{SO}_{2} \mathrm{NH}$ - groups [40], while increased by protonation of $-\mathrm{NH}_{2}$ - groups [41]. At $\mathrm{pH}$ ranges between 4 and 6 , this was not consistent with the order of $K_{d}\left(K_{d}^{0}>K_{d}^{-}>\right.$ $\mathrm{K}_{d}^{+}$) in this study. Thus, $\pi-\pi$ EDA interaction was not the major mechanism for adsorption of SMX onto A-PBC at these $\mathrm{pH}$ ranges. This was also consistent with the previous research [16] which reported the strong hydrophobic interaction between TC and CNTs rather than $\pi-\pi$ EDA interaction. In contrast, previous researches $[42,43]$ reported the possible $\pi-\pi$ EDA interaction between SMX and CMs. Recently, Yoo [44] reported the increasing $\pi-\pi^{*}$ transition (plasmon) intensity after the chemical activation of PBC. Similarly, Peng et al. [45] reported that adsorption is determined mainly by the number or areas of aromatic rings in both antibiotics and adsorbent when the main adsorption mechanism is the $\pi-\pi$ interaction. Collectively, it is reasonable to conclude that the A-PBC in this study with the high surface area $\left(959.9 \mathrm{~m}^{2} / \mathrm{g}\right)$, hydrophobicity and $\mathrm{sp}^{2}$ after the $\mathrm{NaOH}$ activation resulted in high SMX adsorption capacity via possible adsorption mechanisms including hydrophobic interaction, $\pi-\pi$ EDA interaction and hydrogen bonding.

\subsection{Adsorption Kinetics and Isotherms}

To understand the possible adsorption mechanisms and rate-limiting step, the kinetic study for adsorption of SMX onto A-PBC was conducted as described in section 2.5 (Fig. 4). Investigation of adsorption kinetics of SMX and A-PBC interaction using PFO, PSO, Elovich and two-compartment first order are summarized 
Table 2. Summary of Kinetic Parameters of SMX Adsorption on A-PBC

\begin{tabular}{|c|c|c|c|c|c|c|c|c|c|c|c|c|c|c|c|c|}
\hline & & & \multicolumn{8}{|c|}{ Pseudo-first order } & \multicolumn{6}{|c|}{ Pseudo-second order } \\
\hline & \multicolumn{2}{|l|}{$\mathbf{Q}_{\mathrm{e}}{ }^{\mathrm{b}}$} & \multicolumn{3}{|c|}{$\mathbf{Q}_{\mathrm{e}}{ }^{\mathrm{C}}$} & \multirow{2}{*}{\multicolumn{2}{|c|}{$\begin{array}{c}\mathbf{K}_{\mathbf{1}} \\
0.03\end{array}$}} & \multicolumn{2}{|c|}{ SSE } & \multirow{2}{*}{$\mathbf{R}^{2}$} & \multicolumn{2}{|c|}{$\mathbf{Q}_{\mathrm{e}}^{\mathbf{b}}$} & $\mathbf{K}_{2}$ & \multicolumn{2}{|c|}{ SSE } & \multirow{2}{*}{$\begin{array}{c}\mathbf{R}^{\mathbf{2}} \\
0.92\end{array}$} \\
\hline $20^{\mathrm{a}}$ & $191 . \mathrm{c}$ & & & 171 & .08 & & & & .96 & & & 79.69 & $2.89 \times 10^{-4}$ & & & \\
\hline \multirow[t]{3}{*}{$100^{\mathrm{a}}$} & 430.8 & & & 380 & .13 & & 0.03 & & .49 & 0.65 & & 00.30 & $9.74 \times 10^{-5}$ & & & 0.91 \\
\hline & \multicolumn{9}{|c|}{ Elovich } & \multicolumn{7}{|c|}{ Two-compartment first order } \\
\hline & $\mathbf{Q}^{\mathrm{c}}$ & & $\mathbf{a}$ & & $\mathbf{b}$ & & $t_{0}$ & SSE & $\mathbf{R}^{2}$ & $\mathbf{Q}_{\mathrm{e}}^{\mathrm{c}}$ & $F_{\text {fast }}$ & $\mathbf{F}_{\text {slow }}$ & $\mathbf{K}_{\text {fast }}$ & $\mathbf{K}_{\text {slow }}$ & SSE & $\mathbf{R}^{2}$ \\
\hline $20^{\mathrm{a}}$ & 197.79 & 2.43 & $\times 1$ & $10^{3}$ & 0.07 & 6.22 & $\times 10^{-3}$ & 3.25 & 0.98 & 186.56 & 0.8281 & 0.1719 & 163.7 & 0.26 & 3.18 & 0.98 \\
\hline $100^{\mathrm{a}}$ & 445.08 & 1.05 & $\times 1$ & $10^{3}$ & 0.03 & 3.78 & $\times 10^{-2}$ & 7.96 & 0.98 & 417.11 & 0.8475 & 0.1525 & 116.16 & 0.25 & 7.38 & 0.98 \\
\hline
\end{tabular}

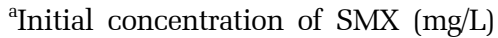

bobserved value

${ }^{\mathrm{c} C a l c u l a t e d}$ value
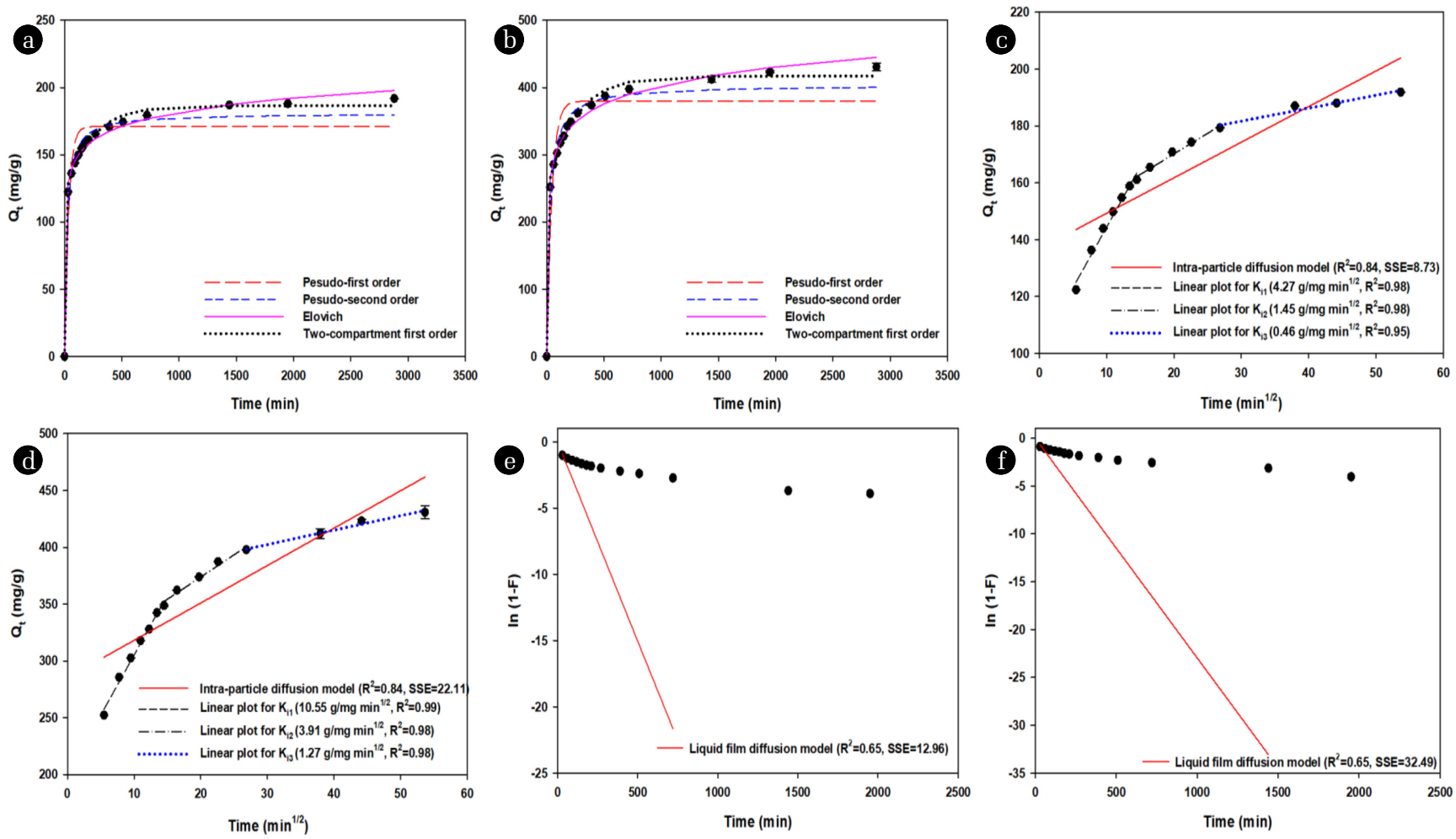

Fig. 4. Adsorption kinetic of SMX on A-PBC by fitting the pseudo-first order, pseudo-second order, Elovich and two-compartment first order ((a) and (b)), intra-particle model ((c) and (d)) and film diffusion model ((e) and (f)). Two different initial concentration $20 \mathrm{mg} / \mathrm{L}$ for (a), (c) and (e) and $100 \mathrm{mg} / \mathrm{L}$ for (b), (d) and (f).

in Table 2. Most of studies reported that kinetic data from sulfonamides adsorption experiment was well-fitted by PSO indicating chemisorptive interaction [7]. As shown in Fig. 4 and Table 2, PSO ( $\mathrm{R}^{2}$ of 0.91-0.92) was more suitable than PFO $\left(\mathrm{R}^{2}\right.$ of 0.65$)$ to described the interaction between SMX and A-PBC. In addition, Elovich was the best fitted kinetic model with lowest SSE (3.25-7.96) and highest $\mathrm{R}^{2}$ (0.98) suggesting that strong chemisorptive interaction occurred on energetically heterogeneous surface of A-PBC [46].

Additionally, the time-courses of SMX adsorption data was analyzed using a two-compartment first order model (Fig. 4(a) and (b)). This model well fitted the dynamics of SMX (20 and
$100 \mathrm{mg} / \mathrm{L})$ on A-PBC with low SSE (3.18-7.38) and high $\mathrm{R}^{2}$ (0.98). The significantly higher $\mathrm{F}_{\text {fast }}(0.83-0.85)$ and $\mathrm{K}_{\text {fast }}(116.16-163.7)$ value than those of $F_{\text {slow }}(0.15-0.17)$ and $K_{\text {slow }}(0.25-0.26)$, indicating that the fast sorption stage was predominant during adsorption process. This was supported by the calculated values from Elovich model (i.e. the higher a (adsorption rate) than b (desorption rate)).

In general, transfer of solutes to adsorbents is usually characterized by liquid film diffusion or intraparticle diffusion. In this study, two diffusion models (intra-particle diffusion and film diffusion) were used to gain insight into the rate-limiting steps affecting the kinetics of SMX adsorption onto A-PBC. As shown in Fig. 4(c)-(f), intra-particle diffusion model was more fitted $\left(\mathrm{R}^{2}\right.$ of 0.84$)$ 


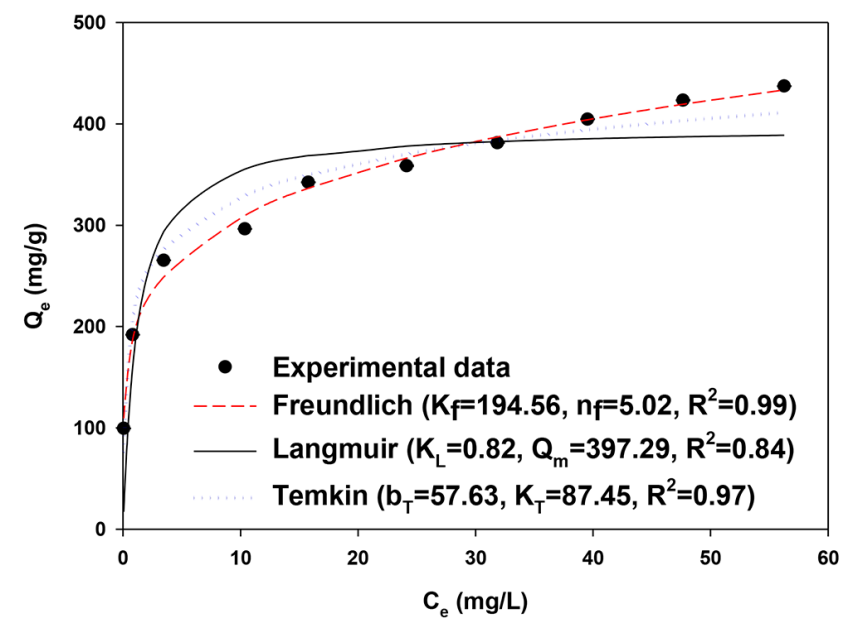

Fig. 5. Adsorption isotherms of SMX on A-PBC by fitting the Freundlich, Langmuir and Temkin models.

to the experimental results than liquid film model $\left(R^{2}\right.$ of 0.65$)$. Thus, intra-particle diffusion would be considered as the major limitation for the adsorption of SMX onto A-PBC. More detailed corresponding rate constants (i.e., $\mathrm{K}_{\mathrm{i} 1}-\mathrm{K}_{\mathrm{i} 3}$ ) (Fig. 4(c) and (d)) derived from linear regression represented the highest constant at the first stage $\left(4.27-10.55 \mathrm{~g} / \mathrm{mg} \mathrm{min}^{1 / 2}\right)$, while rate constants of $2^{\text {nd }}$ (1.45-3.91 $\mathrm{g} / \mathrm{mg} \mathrm{min}^{1 / 2}$ ) and $3^{\text {rd }}$ stages $\left(0.46-1.27 \mathrm{~g} / \mathrm{mg} \mathrm{min}^{1 / 2}\right)$ attributed to the intra-particle diffusion showed low value. Especially, the rate constants of $3^{\text {rd }}$ stage assigned to micropore diffusion was significantly lower than those of the previous two stages. This phenomenon is frequently observed during adsorption of organic contaminants resulted from decreased active adsorption sites on BCs [46].

Several literatures reported that isotherms of SMX adsorption onto various BCs could be fitted into either Langmuir [21] or Freundlich [8, 18-20] model. Based on the type of isotherm of A-PBC (i.e., Type I) (Fig. 5), three phenomenological models including Langmuir (no decrease of heat), Freundlich (a logarithmic decrease of heat) and Temkin (a linear decrease of heat) were applied in this study. The results in Fig. 5 showed Freundlich model was more appropriate than Langmuir and Temkin models indicating that the adsorption may take place on a heterogeneous surface with varied affinities. Based on the $\mathrm{n}_{\mathrm{f}}$ values derived from Freundlich model, the adsorption of SMX was favorable (i.e. the $\mathrm{n}_{\mathrm{f}}$ value within the range 1-10) onto A-PBC with high energetic heterogeneity. Besides, when the results from the isotherm experiments were fitted to Langmuir and Temkin models, the Langmuir constant $\left(\mathrm{K}_{\mathrm{L}}=0.82\right)$ and Temkin constant $\left(\mathrm{b}_{\mathrm{T}}=\right.$ 57.63) suggested the SMX adsorption onto A-PBC would be favorable (i.e., $0<\mathrm{R}_{\mathrm{L}}<1$ ) and adsorption reaction would occur exothermically (i.e., $b_{T}>1$ ) in the concentration range used in this study.

\subsection{Comparison of the SMX Adsorption Capacities of Various CMs}

Table 3 lists the maximum adsorption capacities for SMX and surface areas of CMs. The $\mathrm{Q}_{\mathrm{m}}$ value for A-PBC (397.29 mg/g) was higher than those of various CMs including BC, AC, CNT and graphene oxide. For example, Zheng et al. [8] and Sun et al. [21] reported the $\mathrm{Q}_{\mathrm{m}}$ value of 1.93-4.99 $\mathrm{mg} / \mathrm{g}$ and $0.25-7.40$

Table 3. Maximum Adsorption Capacity $\left(\mathrm{Q}_{\mathrm{m}}\right)$ of $\mathrm{SMX}$ and the Surface Area of Various CMs

\begin{tabular}{|c|c|c|c|}
\hline Carbonaceous materials & Surface area $\left(\mathrm{m}^{2} / \mathrm{g}\right)$ & $Q_{m}(m g / g)$ & References \\
\hline Giant reed $\mathrm{BC}\left(300^{\circ} \mathrm{C}\right)$ & 2.09 & $4.99^{\mathrm{b}}$ & \multirow{2}{*}{ Zheng et al. [8] } \\
\hline Giant reed $\mathrm{BC}\left(600^{\circ} \mathrm{C}\right)$ & 58.75 & $1.93^{\mathrm{b}}$ & \\
\hline Bamboo $\mathrm{BC}\left(\mathrm{H}_{3} \mathrm{PO}_{4}\right.$ activated, $\left.600^{\circ} \mathrm{C}\right)$ & 1.12 & $88.10^{\mathrm{b}}$ & Ahmed et al. [19] \\
\hline Rice-straw BC $\left(300^{\circ} \mathrm{C}\right)$ & 5.76 & $4.21^{\mathrm{b}}$ & \multirow{4}{*}{ Sun et al. [21] } \\
\hline Rice-straw BC $\left(600^{\circ} \mathrm{C}\right)$ & 27.4 & $7.40^{\mathrm{b}}$ & \\
\hline Wheat-straw BC $\left(300^{\circ} \mathrm{C}\right)$ & 7.62 & $6.75^{\mathrm{b}}$ & \\
\hline Wheat-straw BC $\left(600^{\circ} \mathrm{C}\right)$ & 38.1 & $0.25^{\mathrm{b}}$ & \\
\hline Primary paper mill sludge $\mathrm{BC}\left(800^{\circ} \mathrm{C}\right)$ & 209.12 & $1.69^{\mathrm{b}}$ & \multirow{2}{*}{ Calisto et al. [18] } \\
\hline Commercial AC (ChemViron Carbon) & 848.22 & $118^{\mathrm{b}}$ & \\
\hline Anaerobically digested bagasse $\mathrm{BC}\left(600^{\circ} \mathrm{C}\right)$ & $17.66^{\mathrm{c}}$ & $54.38^{\mathrm{b}}$ & Yao et al. [24] \\
\hline Graphene Oxide & - & $240^{\mathrm{b}}$ & Chen et al. [14] \\
\hline Coal based AC (Norit $\left.{ }^{\circledR}\right)$ & 851 & $185.19^{\mathrm{b}}$ & Çalışkan and Göktürk [15] \\
\hline Multi-walled CNTs & 382 & $71.8^{\mathrm{b}}$ & \multirow[t]{3}{*}{ Zhao et al. [1] } \\
\hline R-PBC & 1.4 & $58.91^{\mathrm{a}}$ & \\
\hline A-PBC & 959.9 & $437.36^{\mathrm{a}}, 397.29^{\mathrm{b}}$ & \\
\hline Commercial AC (Calgon F400) & $816.3^{\mathrm{d}}$ & $312.14^{\mathrm{a}}$ & \multirow{4}{*}{ In this study } \\
\hline Commercial AC (Darco® G-60) & $933^{\mathrm{e}}$ & $328.83^{\mathrm{a}}$ & \\
\hline Commercial AC (Norit ${ }^{\circledR}$ CA1) & $980^{\mathrm{f}}$ & $399.94^{\mathrm{a}}$ & \\
\hline Commercial AC (Norit@ GAC) & $1,200^{f}$ & $377.5^{\mathrm{a}}$ & \\
\hline
\end{tabular}

${ }^{\mathrm{a}}$ Derived from experimental data; ${ }^{\mathrm{b}}$ Derived from isotherm model data; ${ }^{\mathrm{c}}[50] ;{ }^{\mathrm{d}}[51] ;{ }^{\mathrm{e}}[52] ;{ }^{\mathrm{f}}[53]$ 
mg/g using the BCs from giant reed and crop residues, respectively. In addition, Çalışkan and Göktürk [15] and Chen et al. [14] achieved the $Q_{\mathrm{m}}$ value of $185.19 \mathrm{mg} / \mathrm{g}$ and $240 \mathrm{mg} / \mathrm{g}$ using commercial $\mathrm{AC}$ and graphene oxide, respectively. From the statistical results (i.e., Pearson correlation) (Fig. S4), the listed surface area showed positive correlation $(\mathrm{r}=0.904, p<0.01)$ with $\mathrm{Q}_{\mathrm{m}}$ value, suggesting that high SMX adsorption capacity on A-PBC could be attributed to its highly increased surface area $\left(959.9 \mathrm{~m}^{2} / \mathrm{g}\right)$ with well-developed porous structure after activation.

To evaluate the feasibility of PBC for adsorption of SMX, the batch adsorption experiments were conducted using four commercial ACs (Calgon F400, Darco ${ }^{\circledR}$ G-60, Norit ${ }^{\circledR}$ CA1 and Norit ${ }^{\circledR}$ GAC) under the same conditions $(0.1 \mathrm{~g} / \mathrm{L}, 100 \mathrm{mg} / \mathrm{L}$ of SMX and $\mathrm{pH}$ 4). As shown in Table 3, the $\mathrm{Q}_{\mathrm{m}}$ of A-PBC $(397.29 \mathrm{mg} / \mathrm{g})$ was comparable to four commercial ACs (312.14 mg/g for Calgon F400, $328.83 \mathrm{mg} / \mathrm{g}$ for Darco ${ }^{\circledR}$ G-60, $377.5 \mathrm{mg} / \mathrm{g}$ for Norit ${ }^{\circledR}$ GAC and Norit ${ }^{\circledR}$ CA1 for $399.94 \mathrm{mg} / \mathrm{g}$ ). Thus, these results supported the A-PBC would have high potential for removal of SMX in wastewater and water after process optimization.

Recently, Ahmed et al. [19] reported that adsorption of SMX onto BCs decreased when containing competing compounds (i.e., sulfamethazine and sulfathiazole) while it was enhanced with low molecular weight organic acids (e.g., citric- and malic acid) [21]. Thus, further investigations will include adsorption of SMX onto A-PBC in various wastewater containing multiple contaminants. In addition, appropriate regeneration processes (e.g., chemical VS thermal) of the A-PBC should be studied to increase their cost effectiveness.

\section{Conclusions}

The NaOH-activated PBC (A-PBC) was prepared and it showed highest adsorption capacity for SMX at $\mathrm{pH} 4$ at which SMX (mostly neutral form of SMX) would be adsorbed onto A-PBC via mainly $\pi-\pi$ and hydrophobic interactions. The kinetic studies showed the Elovich and intraparticle diffusion models were the most appropriate ones indicating the chemisorption of SMX onto surface of A-PBC with diffusion limitation. The Freundlich model was found to be best fitted isotherm model indicating heterogeneous and multiple layer of adsorption. A-PBC demonstrated its high adsorption capacity for SMX which was comparable with commercial ACs.

\section{Acknowledgments}

This work was funded by Texas A\&M University Chancellor Research Initiative Fund and the US-DOE Office of Energy Efficiency and Renewable Energy (Award Number DE-EE0006639).

\section{References}

1. Zhao H, Liu X, Cao Z, et al. Adsorption behavior and mechanism of chloramphenicols, sulfonamides, and non-antibiotic pharmaceuticals on multi-walled carbon nanotubes. J. Hazard.
Mater. 2016;310:235-245

2. Kümmerer K. The presence of pharmaceuticals in the environment due to human use - Present knowledge and future challenges. J. Environ. Manage. 2009;90:2354-2366.

3. Qi C, Liu X, Lin C, et al. Degradation of sulfamethoxazole by microwave-activated persulfate: Kinetics, mechanism and acute toxicity. Chem. Eng. J. 2014;249:6-14.

4. Kumar A, Xagoraraki I. Pharmaceuticals, personal care products and endocrine-disrupting chemicals in US surface and finished drinking waters: A proposed ranking system. Sci Total Environ. 2010;408:5972-5989.

5. Liu J-L, Wong M-H. Pharmaceuticals and personal care products (PPCPs): A review on environmental contamination in China. Environ. Int. 2013;59:208-224.

6. Luo Y, Xu L, Rysz M, Wang Y, Zhang H, Alvarez PJ. Occurrence and transport of tetracycline, sulfonamide, quinolone, and macrolide antibiotics in the Haihe River Basin, China. Environ. Sci. Technol. 2011;45:1827-1833.

7. Peiris C, Gunatilake SR, Mlsna TE, Mohan D, Vithanage M. Biochar based removal of antibiotic sulfonamides and tetracyclines in aquatic environments: A critical review. Bioresour. Technol. 2017;246:150-159.

8. Zheng H, Wang Z, Zhao J, Herbert S, Xing B. Sorption of antibiotic sulfamethoxazole varies with biochars produced at different temperatures. Environ. Pollut. 2013;181:60-67.

9. Akhtar J, Amin NS, Aris A. Combined adsorption and catalytic ozonation for removal of sulfamethoxazole using $\mathrm{Fe}_{2} \mathrm{O}_{3} / \mathrm{CeO}_{2}$ loaded activated carbon. Chem. Eng. J. 2011;170:136-144.

10. Boreen AL, Arnold WA, McNeill K. Photochemical fate of sulfa drugs in the aquatic environment: Sulfa drugs containing five-membered heterocyclic groups. Environ. Sci. Technol. 2004;38:3933-3940.

11. de Amorim KP, Romualdo LL, Andrade LS. Electrochemical degradation of sulfamethoxazole and trimethoprim at boron-doped diamond electrode: Performance, kinetics and reaction pathway. Sep. Purif. Technol. 2013;120:319-327.

12. Putra EK, Pranowo R, Sunarso J, Indraswati N, Ismadji S. Performance of activated carbon and bentonite for adsorption of amoxicillin from wastewater: Mechanisms, isotherms and kinetics. Water Res. 2009;43:2419-2430.

13. Gao J, Pedersen JA. Adsorption of sulfonamide antimicrobial agents to clay minerals. Environ. Sci. Technol. 2005;39: 9509-9516.

14. Chen H, Gao B, Li H. Removal of sulfamethoxazole and ciprofloxacin from aqueous solutions by graphene oxide. J. Hazard. Mater. 2015;282:201-207.

15. Çalışkan E, Göktürk S. Adsorption characteristics of sulfamethoxazole and metronidazole on activated carbon. Sep. Sci. Technol. 2010;45:244-255.

16. Yu X, Zhang L, Liang M, Sun W. pH-dependent sulfonamides adsorption by carbon nanotubes with different surface oxygen contents. Chem. Eng. J. 2015;279:363-371.

17. Tabish TA, Memon FA, Gomez DE, Horsell DW, Zhang S. A facile synthesis of porous graphene for efficient water and wastewater treatment. Sci. Rep. 2018;8:1817.

18. Calisto V, Ferreira CI, Oliveira JA, Otero M, Esteves VI. Adsorptive removal of pharmaceuticals from water by com- 
mercial and waste-based carbons. J. Environ. Manage. 2015;152:83-90.

19. Ahmed MB, Zhou J, Ngo HH, Guo W, Johir MAH, Sornalingam K. Single and competitive sorption properties and mechanism of functionalized biochar for removing sulfonamide antibiotics from water. Chem. Eng. J. 2017;311:348-358.

20. Lian F, Sun B, Song Z, Zhu L, Qi X, Xing B. Physicochemical properties of herb-residue biochar and its sorption to ionizable antibiotic sulfamethoxazole. Chem. Eng. J. 2014;248:128-134.

21. Sun B, Lian F, Bao Q, Liu Z, Song Z, Zhu L. Impact of low molecular weight organic acids (LMWOAs) on biochar micropores and sorption properties for sulfamethoxazole. Environ. Pollut. 2016;214:142-148.

22. Xie M, Chen W, Xu Z, Zheng S, Zhu D. Adsorption of sulfonamides to demineralized pine wood biochars prepared under different thermochemical conditions. Environ. Pollut. 2014;186: 187-194.

23. Shimabuku KK, Kearns JP, Martinez JE, Mahoney RB, Moreno-Vasquez L, Summers RS. Biochar sorbents for sulfamethoxazole removal from surface water, stormwater, and wastewater effluent. Water Res. 2016;96:236-245.

24. Yao Y, Zhang Y, Gao B, Chen R, Wu F. Removal of sulfamethoxazole (SMX) and sulfapyridine (SPY) from aqueous solutions by biochars derived from anaerobically digested bagasse. Environ. Sci. Pollut. Res. 2018:25:25659-25667.

25. Thangalazhy-Gopakumar S, Adhikari S, Ravindran H, et al. Physiochemical properties of bio-oil produced at various temperatures from pine wood using an auger reactor. Bioresour. Technol. 2010;101:8389-8395.

26. MartÍnez F, GÓmez A. Estimation of the solubility of sulfonamides in aqueous media from partition coefficients and entropies of fusion. Phys. Chem. Liq. 2002;40:411-420.

27. Jang HM, Yoo S, Choi Y-K, Park S, Kan E. Adsorption isotherm, kinetic modeling and mechanism of tetracycline on Pinus taeda-derived activated biochar. Bioresour. Technol. 2018;259: 24-31.

28. ASTM. Standard test methods for proximate analysis of coal and coke by macro thermogravimetric analysis. West Conshohocken: ASTM International; 2016.

29. Marriott A, Hunt A, Bergström E, et al. Investigating the structure of biomass-derived non-graphitizing mesoporous carbons by electron energy loss spectroscopy in the transmission electron microscope and X-ray photoelectron spectroscopy. Carbon 2014;67:514-524.

30. Yoo S, Kelley SS, Tilotta DC, Park S. Structural characterization of loblolly pine derived biochar by X-ray diffraction and electron energy loss spectroscopy. ACS Sustain. Chem. Eng. 2018;6:2621-2629.

31. Zhang Z-l, Brydson R, Aslam Z, et al. Investigating the structure of non-graphitising carbons using electron energy loss spectroscopy in the transmission electron microscope. Carbon 2011;49:5049-5063.

32. Daniels H, Brydson R, Rand B, Brown A. Investigating carbonization and graphitization using electron energy loss spectroscopy (EELS) in the transmission electron microscope (TEM). Philos. Mag. 2007;87:4073-4092.

33. Teixidó M, Pignatello JJ, Beltrán JL, Granados M, Peccia J.
Speciation of the ionizable antibiotic sulfamethazine on black carbon (biochar). Environ. Sci. Technol. 2011;45:10020-10027.

34. Zhu X, Liu Y, Zhou C, Luo G, Zhang S, Chen J. A novel porous carbon derived from hydrothermal carbon for efficient adsorption of tetracycline. Carbon 2014;77:627-636.

35. Park J, Hung I, Gan Z, Rojas OJ, Lim KH, Park S. Activated carbon from biochar: Influence of its physicochemical properties on the sorption characteristics of phenanthrene. Bioresour. Technol. 2013;149:383-389.

36. Keiluweit M, Nico PS, Johnson MG, Kleber M. Dynamic molecular structure of plant biomass-derived black carbon (biochar). Environ. Sci. Technol. 2010;44:1247-1253.

37. Ji L, Liu F, Xu Z, Zheng S, Zhu D. Adsorption of pharmaceutical antibiotics on template-synthesized ordered micro-and mesoporous carbons. Environ. Sci. Technol. 2010;44:3116-3122.

38. Ji L, Chen W, Duan L, Zhu D. Mechanisms for strong adsorption of tetracycline to carbon nanotubes: A comparative study using activated carbon and graphite as adsorbents. Environ. Sci. Technol. 2009;43:2322-2327.

39. Chen W, Duan L, Wang L, Zhu D. Adsorption of hydroxyl-and amino-substituted aromatics to carbon nanotubes. Environ. Sci. Technol. 2008;42:6862-6868.

40. Ji L, Chen W, Zheng S, Xu Z, Zhu D. Adsorption of sulfonamide antibiotics to multiwalled carbon nanotubes. Langmuir 2009;25:11608-11613.

41. Hansch C, Leo A, Taft R. A survey of Hammett substituent constants and resonance and field parameters. Chem. Rev. 1991;91:165-195.

42. Reguyal F, Sarmah AK. Adsorption of sulfamethoxazole by magnetic biochar: Effects of $\mathrm{pH}$, ionic strength, natural organic matter and 17 $\alpha$-ethinylestradiol. Sci. Total Environ. 2018;628: 722-730.

43. Chen H, Gao B, Li H. Functionalization, pH, and ionic strength influenced sorption of sulfamethoxazole on graphene. J. Environ. Chem. Eng. 2014;2:310-315.

44. Yoo S. Structural characterizations of biomass-derived carbon materials and application as supercapacitor electrode [dissertation]. USA: North Carolina State Univ.; 2018.

45. Peng B, Chen L, Que C, et al Adsorption of antibiotics on graphene and biochar in aqueous solutions induced by $\pi-\pi$ interactions. Sci. Rep. 2016;6:31920.

46. Zhou Y, Liu X, Xiang Y, et al. Modification of biochar derived from sawdust and its application in removal of tetracycline and copper from aqueous solution: Adsorption mechanism and modelling. Bioresour. Technol. 2017;245:266-273.

47. Enders A, Hanley K, Whitman T, Joseph S, Lehmann J. Characterization of biochars to evaluate recalcitrance and agronomic performance. Bioresour. Technol. 2012;114:644-653.

48. Harvey OR, Herbert BE, Rhue RD, Kuo L-J. Metal interactions at the biochar-water interface: Energetics and structure-sorption relationships elucidated by flow adsorption microcalorimetry. Environ. Sci. Technol. 2011;45:5550-5556.

49. Yang X, Xu G, Yu H, Zhang Z. Preparation of ferric-activated sludge-based adsorbent from biological sludge for tetracycline removal. Bioresour. Technol. 2016;211:566-573.

50. Inyang M, Gao B, Pullammanappallil P, Ding W, Zimmerman AR. Biochar from anaerobically digested sugarcane bagasse. 
Bioresour. Technol. 2010;101:8868-8872.

51. Gauden PA, Szmechtig-Gauden E, Rychlicki G, Duber S, Garbacz JK, Buczkowski R. Changes of the porous structure of activated carbons applied in a filter bed pilot operation. J. Colloid Interface Sci. 2006;295:327-347.

52. Oliveira LCA, Rios RVRA, Fabris JD, Garg V, Sapag K, Lago
RM. Activated carbon/iron oxide magnetic composites for the adsorption of contaminants in water. Carbon 2002;40:2177-2183. 53. Gicheva G, Yordanov G. Removal of citrate-coated silver nanoparticles from aqueous dispersions by using activated carbon. Colloids Surf. A 2013;431:51-59. 